\title{
NOCTURNAL PANIC ATTACKS
}

\author{
Fabiana L. Lopes ${ }^{1}$, Antonio E. Nardi', Isabella Nascimento', \\ Alexandre M. Valença' ${ }^{1}$, Walter A Zin ${ }^{2}$
}

\begin{abstract}
The panic-respiration connection has been presented with increasing evidences in the literature. We report three panic disorder patients with nocturnal panic attacks with prominent respiratory symptoms, the overlapping of the symptoms with the sleep apnea syndrome and a change of the diurnal panic attacks, from spontaneous to situational pattern. The implication of these findings and awareness to the distinct core of the nocturnal panic attacks symptoms may help to differentiate them from sleep disorders and the search for specific treatment.
\end{abstract}

KEY WORDS: sleep panic attack, respiration, ventilation, carbon dioxide, nortriptyline.

\begin{abstract}
Ataques de pânico noturno
RESUMO - A conexão pânico-respiração vem apresentando evidências crescentes na literatura. Nós relatamos três pacientes com transtorno de pânico com ataques de pânico no sono com sintomas respiratórios proeminentes, a sobreposição de sintomas com a síndrome de apnéia do sono e a mudança dos ataques de pânico em vigília, de um padrão espontâneo a situacional. A implicação destes achados e a necessidade de maior atenção para o conjunto distinto de sintomas dos ataques de pânico no sono poderá ser útil para o diagnóstico diferencial e na busca por tratamento específico.
\end{abstract}

PALAVRAS-CHAVE: ataque de pânico no sono, respiração, ventilação, dióxido de carbono, nortriptilina.

The connection between respiratory system and panic disorder has been reported in the medical literature ${ }^{1,2}$. The panic disorder (PD) presents an heterogeneous cluster of symptoms and a classification based on subtypes has been suggested ${ }^{3-5}$. The "prominent respiratory symptoms" group appears as a distinct subtype ${ }^{4}$ presenting more scientific evidence than any other group ${ }^{4-6}$. Biber \& Alkin ${ }^{5}$ examined the sensitivity to $\mathrm{CO}_{2}$ in panic disorder patients throughout the proposed subtypes' model. Patients with panic disorder with prominent respiratory symptoms were more sensitive to the $\mathrm{CO}_{2}$ challenge, had a significantly longer duration of illness, more severe panic and phobic symptoms and were more likely to be heavier smokers than were patients with non respiratory symptoms. Biber \& Alkin ${ }^{5}$ also suggest that panic disorder patients with prominent respiratory symptoms have more spontaneous and nocturnal panic attacks and that it might be related to a more severe and disabling subtype of panic disorder.
The nocturnal panic attacks have been presenting as a peculiar group exhibiting a more closer relationship with the respiratory system. Mellman \& Uh$\mathrm{de}^{7}$ suggest the nocturnal panic might be a variant of panic disorder ${ }^{7,8}$. There may be a point to a greater irregularity of respiratory pattern during sleep in patients with panic disorder, ${ }^{2,}{ }^{10}$. Stein et al. ${ }^{2}$ suggest that irregular nocturnal respiration may not be a feature of all panic disorder patients but rather, might be confined to a subgroup. A greater severity of panic disorder among those patients who do experience panic attacks during sleep than those who do not is also well documented in the literature ${ }^{5,9}$, and is suggested that daytime and nocturnal panic attacks developed along different evolutionary pathways $^{8}$. Biological factors as an autonomic nervous system dysfunction might be a crucial aspect in the case of nocturnal panic attacks while psychological and cognitive factors are pointed as a possible initial stimulus for daytime panic attack ${ }^{8}$. This tailored 'Laboratory of Panic \& Respiration. Institute of Psychiatry, Federal University of Rio de Janeiro (UFRJ), Rio de Janeiro RJ, Brazil; ${ }^{2}$ Laboratory
of Respiration Physiology. Carlos Chagas Filho Biophysics Institute UFRJ. Supported by the Brazilian Council for Scientific and Technological
Development (CNPq), Grant 300500/93-9.

Received 20 February 2002, received in final form 19 April 2002. Accepted 7 May 2002.

Dra. Fabiana Leão Lopes - Laboratory of Panic \& Respiration UFRJ - Rua Visconde de Pirajá 407/702 - 22410-003 Rio de Janeiro RJ - Brasil - FAX: 5521-2523-6839. E-mail:aenardi@novanet.com.br 
approach sheds light on practical clinical questions such as an early detection, an accurate diagnosis and different forms of treatment.

We aim to demonstrate the connection between the respiratory symptoms and noturnal panic attacks, through the description of three clinical cases of panic disorders (DSM-IV), from the Laboratory of Panic \& Respiration of the Institute of Psychiatry of the Federal University of Rio de Janeiro.

\section{CASES}

Case A. Patient A, 42 year-old, female, caucasian. Her first panic attack was six-years ago. She started with spontaneous awake attacks with palpitations, shortness of breath, choking, chest pain, dizziness and fear of losing control. She underwent several laboratory exams, all normal ones. She developed thereafter, panic attacks during sleep associated to her awake panic attacks. At this time, she did not submit for medical treatment. Her nocturnal panic attacks became more intense, until daily attacks with prominent respiratory symptoms (shortness of breath, chest pain, tingling, fear of dying and losing control and severe choking). An atypical agoraphobic pattern developed and she could only sleep if in orthopnea - "I sleep almost or completed seated, leant by a lot of pillows in a light room" - she said. On the other hand, her awake panic attacks changed from a spontaneous pattern to situational attacks with nausea, diarrhea, dizziness and tachycardia when in closed or crowded places, as in a bus. She also presented classical agoraphobic symptoms while awake avoiding being alone and crowded or closed places. The patient also presented anticipating anxiety related at nightfall. She also complained of frontal headache and difficulty to concentrate. She was initially treated wit nortriptyline $10 \mathrm{mg}$ daily. At the dosage of $75 \mathrm{mg} /$ day she achieved remission of the nocturnal panic attacks but was still presenting limited symptom attacks related to stressful and threaten places or situations. At $100 \mathrm{mg} /$ day she experienced a full remission of the panic attacks.

Case B. Patient B, 24 year-old, male, caucasian. The patient presented with a chief complaint of choking and shortness of breath while sleeping. He had been presenting panic attacks for two months, during sleep, with several physical and cognitive symptoms (dyspnea, choking, paresthesias, sweating, tachycardia and severe fear of dying). He reported about five panic attacks per week. Concomitantly, he noticed an increasing on the blood pressure's levels of the arterial blood pressure without a positive previous history for arterial hypertension. He underwent laboratory exams, which were all normal. Intense fear and persistent worry to present a panic attack during the sleep marked the clinical presentation. Therefore, he changed his schedule and began to work on his daily activities at the night, thus avoiding to sleep. A diurnal drowsiness was added to his clinical picture associated to a difficulty in maintain concentration. Thus, the patient had to cancel his enrollment at the university. Treatment with nortriptyline $10 \mathrm{mg}$ daily was instituted with a gradual increase of the dosage. The patient experienced an improvement in the frequency and intensity of the panic attacks at the dose of $20 \mathrm{mg} /$ day. At this time he exhibited a change in his symptomatological pattern, with remission of the respiratory symptoms. Instead, he developed nocturnal panic attacks with dizziness, tremor, tachycardia, sweating, depersonalization and fear of losing control and going crazy. When was reached $75 \mathrm{mg} /$ day, a complete remission of the panic attacks, agoraphobia and anticipating anxiety was achieved and the patient has been free of any panic attacks in one year follow-up.

Case C. Patient C, 45 year-old, female, caucasian. The patient presented with spontaneous, awake and daily panic attacks with the presence of cold flushes, sweating, diarrhea, choking, dyspnea, occasional tachycardia and fear of losing control for two years. She evolved to more severe panic attacks during sleep that had prominent respiratory symptoms as choking, fear of dying, dyspnea, and paresthesias. Sweating and cold flushes were also present. She was admitted to emergency rooms several times worried about the physical consequences of the panic attacks. She reported an extreme fear of closed or dark places, specially related to the night. She said : "I am afraid to choke myself, I live with this fear and remain thinking if happens a black-out...". During wakefulness, she started to present situational panic attacks related to closed or crowded places, with a distinct profile of symptoms (cold flushes, shaking, diarrhea and urge to flee). A complaint of daily occipto-temporal headache, frequent mild forgetfulness referred as "blanks in the memory and difficulty to concentrate", and also initial and middle insomnia were overlapped to her clinical picture. She was initially treated with nortriptyline reaching the dosage of $100 \mathrm{mg}$ daily. Since then, the patient has experienced a complete recovery of the panic attacks, cognitive complaints and the pattern of headache. In an one-year follow-up she is completed free of panic attacks and the agoraphobic symptoms are improving.

\section{DISCUSSION}

These case reports draw attention for three major findings of the nocturnal panic attacks: (1) the presence of the prominent respiratory symptoms, (2) the overlapping to the sleep disorders symptoms and, (3) a change to the clinical presentation of the diurnal panic attacks, from spontaneous to situational pattern.

All the cases presented a strong association with the respiratory symptoms, suggesting a direct relationship to Klein's false suffocation alarm theory ${ }^{11}$. Since Klein's theory predicts that patients with panic 
disorder would exhibit irregular breathing patterns not only during wakefulness, but during sleep as well ${ }^{2,11}$. These cases lend support to the notion suggested by Biber \& Alkin ${ }^{5}$, which panic patients with prominent respiratory symptoms also have more spontaneous and nocturnal panic attacks ${ }^{5,12}$; nevertheless, the cases confront with others studies who state that nocturnal and daytime panic attacks have similar presentation and symptomatology ${ }^{8}$. A history of traumatic suffocation experiences and nocturnal panic attacks associated with the predominantly respiratory subtype have been reported ${ }^{5,10,13}$. The respiratory symptoms have been suggested as more cardinal than others to the therapeutic process just as some of them have been found to be more important for diagnostic considerations ${ }^{14}$. Mavissakalian ${ }^{14}$ points that respiratory symptoms, most strongly dyspnea and choking, displayed the highest degree of early differentiation between effective and innefective doses of the drug ${ }^{14,15}$. This is illustrated by our case $B$, who presented remission of the respiratory symptoms following the beginning of pharmacotherapy. We decided to use the nortriptyline due to the efficacy of the tryciclics in the treatment of the panic disor$\operatorname{der}^{16}$ and mild sleep apnea syndrome ${ }^{17,18}$. The protriptyline has pointed as effective in patients with sleep apnea when the disorder is not life-threatening, but its anticholinergic side-effects worsened the adherence to the treatment. The nortriptyline appears to be well tolerated.

We observed overlapping symptomatological features of the nocturnal panic attacks and sleep apnea syndrome, as the nocturnal and diurnal symptoms. Among the nocturnal symptoms, there were the sensation of choking or drowning associated to nocturnal awaken and an initial and middle insomnia. Otherwise, among the diurnal symptoms there were a drowsiness, presented in the case $B$, and cognitive symptoms as the difficulty to concentrate, mild forgetfulness and a pattern of frontal headache. An increase in the levels of the arterial blood pressure was also present, as was stated in the case $B$.

Cognition is the mental process by which an individual acquires knowledge and understanding of their physical, cultural, social and psychological world $^{19}$. The cognitive system not only endows awareness of the present situation, but also, via the process of memory, a recollection of previous events and experiences ${ }^{19}$. So, the memory, attention and concentration are included in the cognitive process. The anxious patients present a progressive breakdown of the integrity of the cognitive system with the subject exhibiting symptoms of uncertainty, apprehension, distress and a diminished cognitive ability leading to erroneous perceptions and judgements about the future ${ }^{19}$. The sleep-apnea patients do also have an attention deficit ${ }^{20}$, presenting as the PD patients, an impairment of the cognitive system.

A hypothesis to justify these findings consists in the pathophysiology of the sleep, when blood $\mathrm{CO}_{2}$ rises significantly ${ }^{10,21}$. The panic disorder patients who have heightened $\mathrm{CO}_{2}$ sensitivity $2,5,10$, according to Klein's false suffocation alarm theory ${ }^{11}$, start a cycle in which enhanced $\mathrm{CO}_{2}$ leads to more frequent sighting in an attempt to reduce arterial $\mathrm{CO}_{2}$ levels ${ }^{2}$. The reduced $\mathrm{CO}_{2}$ results in breathing pauses that occur because the $\mathrm{CO}_{2}$ stimulus for breathing is withdrawn ${ }^{2}$. The pauses are, in turn, sufficient to arouse a hypoxia state and to increase the pleura's pressure, causing a significant ventilatory stress ${ }^{22}$. These findings are also sufficient to make active the false alarm of the sensitive patients triggering, in consequence, the nocturnal panic attacks.

Some authors emphasize the need to recognize the sleep apnea syndrome (SAS) as an important differential diagnosis of the panic disorder that occur during the sleep ${ }^{8,23,24}$. Edlund et al..$^{24}$ in a survey of 301 subjects with SAS demonstrated that obstructive sleep apnea cause symptoms of nocturnal panic attacks. Stein et al. ${ }^{2}$ examined the nocturnal breathing patterns of panic disorder patients conducting a respiratory polisomnography on 14 patients with panic disorder and 14 healthy control subjects. They found that none of the patients had clinically serious apneic episodes, but two of the three patients with recent sleep panic attacks had microapnea/ microhypopnea index scores higher than those of any of the other subjects. They conceived that the "subclinical" microapneic and microhypopneic episodes might be associated with brief arousals sufficient to "alarm" sensitive patients and to consequently result in nocturnal panic attack. Cassano et al. ${ }^{23}$ encompass the nocturnal panic attacks in the panicagoraphobic spectrum. They consider these clinical manifestations as variants of panic attacks and suggest that this often neglected spectrum may have unrecognized importance in treatment selection and response ${ }^{23}$.

The respiratory polysomnography is considered the gold pattern to the diagnosis of the sleep apnea syndrome. As our patients were not submitted yet to this sleep study, the differential diagnosis become extremely worsened. 
A third key finding of this study is a change of the clinical picture of the daytime panic attacks. After the beginning of nocturnal panic attacks, the patients start to present situational wake panic attacks with the predominance of physical symptoms. Norton et al. ${ }^{25}$ examined two groups of diurnal panic attacks patients, with and without nocturnal panic attacks. They found that the nocturnal panic group experienced more symptoms during expected diurnal panic attacks, but not during unexpected/spontaneous diurnal panic attacks ${ }^{25}$.

We speculate that nocturnal panic attacks constitute an isolated entity with predominantly respiratory and cognitive symptoms and a pattern of atypical agoraphobia, and also presenting a more defined biologic mechanism. On the other hand, daytime panic attacks appear to be more influenced by environmental factors. A possible explanation is that they represent different phenotypical expressions of the poly/oligogenic model, belong the panic spectrum. These data agree with Shapiro et al. ${ }^{8}$ in regard to the different evolutionary pathways and may guide the therapeutic process, since daytime panic attacks seem to be more related to the environment and prone to present a positive outcome to the cognitive behavioral therapy. The nocturnal panic attacks appear to need a specific pharmacological approach. However, more patients with sleep panic attacks should be studied, more respiratory polysomnography should be done, and more $\mathrm{CO}_{2}$ challenge as a biological phenotype should be conducted.

In conclusion, the nocturnal panic attacks are common in panic disorder patients and are often neglected or misdiagnosed, due to a phobic pattern of these patients in which they do not complain about their sleep, or to a misunderstanding of the physician. So, these reports highlight the need for greater attention to the distinct core of symptoms of the nocturnal panic attacks, improving its diagnosis and treatment.

\section{REFERENCES}

1. Gorman JM, Fyer MR, Goetz R, et al. Ventilatory phisiology of patients with of panic disorder. Arch Gen Psychiatry 1988;45:31-39.

2. Stein MB, Millar TW, Larsen DK, Kryger MH. Irregular breathing during sleep in patients with panic disorder. Am J Psychiatry 1995; 152:1168-1173.

3. Aronson TA, LogueJM. Phenomenology of panic attacks: a descriptive study of panic disorder patients' self report. J Clin Psychiatry 1988;49:8-13.

4. Briggs AC, Stretch DD, Brandon S. Subtyping of panic disorder by symptom profile. Br J Psychiatry 1993;163:201-209.

5. Biber B, Alkin T. Panic disorder subtypes: differential responses to $\mathrm{CO} 2$ challenge. Am J Psychiatry 1999; 156:739-744.

6. Bovasso G, Eaton W. Types of panic attacks and their association with psychiatric disorder and physical illness. Compr Psychiatry 1999;6:469-477.

7. Mellman TA, Uhde TW. Patients with frequent sleep panic: clinical findings and response to medication treatment. J Clin Psychiatry 1990;51:513-516

8. Shapiro CM, Sloan EP. Nocturnal panic: an underrecognized entity. J Psychosom Res 1998;44:21-23.

9. Ley R. Panic attacks during sleep: a hyperventilation: probability model. J Behav Ther Exp Psychiatry 1988;19:181-192.

10. Preter M, Klein DF. Panic disorder and the suffocation false alarm theory: current state of knowledge and further implications for neurobiologic theory testing. In Bellodi L, Perna G, (eds). The panic respiration connection. Milan: MDM Medical Media, 1998:1-24.

11. Klein DF. False suffocation alarms, spontaneous panics, and related conditions: an integrative hypothesis. Arch Gen Psychiatry 1993;50:306-317.

12. Valença AM, Nardi AE, Nascimento I, Mezzasalma MA, Lopes FL, Zin W. Ataques de pânico provocados pelo dióxido de carbono: um estudo clínico - fenomenológico. Rev Bras Psiquiatria 2001;23:15-20.

13. Bouwer C, Stein DJ. Association of panic disorder with a history of traumatic suffocation. Am J Psychiatry 1997;154:1566-1570.

14. Mavissakalian MR. Phenomenology of panic attacks: responsiveness of individual symptoms to imipramine. J Clin Psychopharmacol 1996;16:233-237.

15. Gorman JM, Browne ST, Papp LA, et al. Effects of antipanic treatment on response to carbon dioxide. Biol Psychiatry 1997;42:982-991.

16. Mavissakalian MR, Perel JM, Talbott-Green M, Sloan C. Gauging the effectiveness of extended imipramine treatment for panic disorder with agoraphobia. Biol Psychiatry 1998;43:848-854.

17. Brownell LG, West P, Sweatman P, Acres JC, Kryger MH. Protriptyline in obstructive sleep apnea : a double-blind trial. N Engl J Med 1982;307:1037-1042.

18. Brownell LG, Perez-Padilla R, West P, Kryger MH. The role of protriptyline in obstructive sleep apnea. Bull Eur Physiopathol Respir 1983;19:621-624.

19. Hindmarch I, Cockle SM, Stanley N. The anatomy of a clinical trial. Hum Pschopharmacol Clin Exp1999;14:S103-S108.

20. Mihaicuta S, Tudoreiche U, Muntean D, Melcescu E, Buner C. Test for determination of attention in patients with sleep apnea syndrome. Pneumologia 2001;50:75-78.

21. Mellman TA, Uhde TW. Eletroencephalographic sleep in panic disorder: a focus on sleep related panic attacks. Arch Gen Psychiatry 1989;46:178-184.

22. Souza MM, Reimão R. Manifestações neuropsíquicas na apnéia do sono. In Reimão R, (ed): Temas de medicina do sono. São Paulo: Lemos, 2000:201-205.

23. Cassano GB, Frank E, Maser JD, et al. The panic-agoraphobic spectrum. Hum Psychopharmacol Clin Exp 1999;14:S38-S44.

24. Edlund MJ, Mc Namara ME, Millman RP. Sleep apnea and panic attacks. Compr Psychiatry 1991;32:130-132.

25. Norton GR, Norton PJ, Walker JR, Cox BJ, Stein MB. A comparison of people with and without nocturnal panic attacks. J Behav Ther Exp Psychiatry 1999;30:37-44. 